\title{
QUERELAS DA DISSONÂNCIA: NIETZSCHE, WAGNER, TRAGÉDIA E MÚSICA
}

\author{
Antonio Manoel Nunes \\ Museu de República - RJ
}

Dois amantes, ignorando que se amam, acreditando em vez disso que cada qual está profundamente ferido e ofendido, desejam reciprocamente que bebam a poção da Morte sob o pretexto de se reconciliarem diante de suas mútuas injúrias, mas arrastados na verdade por um motivo inconsciente: desejam se libertar, pela morte, de toda futura separação e ambição. A crença de que a morte está próxima liberta suas almas e lhes traz uma breve, terrivel felicidade, como se realmente tivessem escapado do dia, da decepção, até da própria vida.

(Friedrich Nietzsche) 


\author{
A B ERTURA \\ Por que devo sofrer este inferno \\ que nenhum céu pode restaurar? \\ Por que esta desonra \\ que nenhuma miséria pode expiar? \\ Quem tornará conhecida do mundo \\ a imperscrutável, profunda, \\ secreta causa? \\ (Tristão e Isolda)
}

Certamente, ao se realizar uma arqueologia da paixão no ocidente, a história de Tristão e de sua amada Isolda estaria no âmago e na origem deste abismático e secreto sentimento que é capaz de corroer desde nobres almas de folhetim até o mais comum homem do cotidiano. Sua força de sedução capta o amador no momento mais insano do entrechoque vida e morte, atirando-o feito pedra ao fundo do fundo do ser.

Desde o século VII, a lenda dos amantes Tristão e Isolda ressoa na comunidade bárbara como a preparar e sedimentar uma rede de sentido que irá atravessar culturas e gerações que, catarticamente, sofrem e incorporam este modelar exemplo de história passional, onde um estigmatizado casal é capaz de se amar desesperadamente, lutar com o mundo exterior a ele e morrer de tanto amar.

Trapaceira e sorrateiramente, a linguagem literária invade, no século XII, a intimidade e o universo da lenda celta, caçando-a, aprisionando-a em seus tentáculos duros, afiados, cristianizados. Assim, na comunhão entre mito e escrita - mediada pelas lentes oblíquas, tempestivas e punidoras do cristianismo -, surge Tristão e Isolda, enquanto texto e modelo de amar e de sofrer, que as narrativas romântica e de massa conseguiram clicherizar ao extremo, despindo-a de suas implicações tanto religiosas quanto existenciais.

Richard Wagner é quem, mais apuradamente, resgata a antiga história medieval, a partir da versão do poeta Gottfried feita no século XIII. Wagner tempera a trama de amor, paixão e morte com doses, às vezes extremadas, da filosofia do pessimismo de Schopenhauer. Para tanto, atualiza a "heresia dualista", incrustrada na lenda, a partir de "uma explícita postura budista da qual o cristianismo, no melhor espírito herético, não seria mais que ressonância"1. Em Schopenhauer, a "origem" do espírito trágico estaria em derrubar a farsa da ilusão de que a vida ofereceria uma plena satisfação ao homem.

O anseio do Nada, o impulso ao nirvana que a sabedoria trágica ensina e a busca da 'expressão estática' desse 'estado de ânimo (...) induzido por Schopenhauer seriam os motivos inspiradores do Tristão' 2 .

Schopenhauer confirma então a Wagner idéias e crenças que por muito tempo o compositor tinha apenas esboçado intuitivamente, oferecendo-lhe consolo metafísico em um quadro de intenso conflito entre amor e dor, vida e morte.

Assim, a tríade tragédia, paixão e música da composição operística wagneriana acaba por funcionar como pedra de toque para que Nietzsche vislumbrasse, nesta obra, o retorno do adormecido dionisismo grego. O poema dramático Tristão e Isol$d a$ funciona, então, como o filtro mágico do amor que irá unir o filósofo Nietzsche a Wagner, como mostra a Origem da tragédia em algumas de suas passagens:

Entre esta música e a nossa mais alta emoção musical, interpõe-se aqui o mito trágico e o herói trágico, e, no fundo, somente como símbolos dos dados mais universais, dos fenômenos mais gerais que só a música pode diretamente exprimir. (...) Graças a esta admirável ilusão apolínea, cremos ver o mundo dos sons avançar para nós debaixo de forma de um mundo plástico e parecenos que nele, como na mais delicada e mais expressiva matéria, tenha sido moldada e esculpida só a aventura de Tristão e Isolda. É assim que o espírito apolíneo nos arranca à universalidade do estado dionisíaco e nos

1. WISNIK, 1987. p.215.

2. Ibidem., p. 216. 
entusiasma pelos indivíduos (...) Pelo poder desconhecido da imagem, da idéia, do ensinamento ético, da emoção apiedada, o espírito apolíneo distrai o homem da orgiástica aniquilação de si próprio e, a despeito do caráter universal das contingências dionisíacas, leva-o a imaginar que vê um quadro isolado do mundo real, por exemplo, Tristão e Isolda, e a crer que o papel da música é simplesmente o de lhe fazer ver melhor e discernir mais profundamente. ${ }^{3}$

Portanto, sob o signo da paixão, que modula o amor e o ódio, a vida e a morte, a ortodoxia e a heresia, navegam Tristão e Isolda, Nietzsche e Wagner. Mar e embarcação assumem, na obra do compositor, símbolos sublimados de um destino fatalista que o próprio Nietzsche confirmou: "Somos dois navios cada um dos quais com seu objetivo e a sua rota particular". ${ }^{4}$

\section{PRIMEIRO ATO}

Lástima, eleva-se a paixão selvagem do dia, pálida e temível, para mim; sua estrela, ostentosa e falsa, leva meu cérebro à decepção e à desilusão!

Maldito dia, com tua claridade!

(Tristão e Isolda)

Ao escolher a cidade de Bayreuth para sediar o teatro que serviria ao seu projeto de eloqüência cenográfico e musical da germanidade, Wagner baseou-se na posição geográfica e simbólica dessa cidade. Localizada entre Munique e Berlim, Bayreuth abrigou, entre 1872 e 1876, a construção de uma grande casa de espetáculos cênicos, onde se montaria pela primeira vez o Anel dos Nibelungos.

3. NIETZSCHE, 1972. p. 157-8.

4. NIETZSCHE, 1977. p. 181.
Richard Wagner via, na montagem desta tetralogia dramático-musical ${ }^{5}$, a oportunidade de celebração da utópica unidade germânica e da fusão da Prússia com a Baviera que havia se processado. Recaindo sobre o mais vetusto mito de criação do povo germânico, o compositor resgatava, através da tonalidade acumuladora e grandiloqüente de sua obra, o espírito de nacionalidade e unidade que, por séculos, estava adormecido.

Da mesma forma que amizades e amores se encaixaram na vida de Wagner através do estigma do drama ou pela intensidade da carga de afeto, sua relação com o então jovem Frederico Nietzsche vai ser marcada pela passional conjugação de amor e ódio, e pela impossibilidade de concretude do ideal/encontro amoroso, tal qual se apresentava nas tramas centrais da vasta obra do compositor.

Em novembro de 1868, Wagner acaba conhecendo o filólogo em Leipzig, na casa de seu cunhado Brockhaus. Nietzsche fora seduzido e conquistado desde o momento em que assistira às apresentações de Tristão e Isolda e Os mestres cantores. Nascia a partir daí mais um wagneriano ardente e mais um relacionamento marcado pelo signo fatal do desencontro.

Sua primeira visita à casa do compositor, na Baviera, foi, segundo biógrafos, marcada simbolicamente pela predestinação trágica. Afirma-se que, no instante em que Nietzsche se fazia anunciar, o ambiente se impregnava de acordes de um tema desconhecido que muito tempo depois iria reconhecer. Aquilo

que ouvia (...) era a canção de Brunnehild despertada por Siegfried: 'Aquele que me acorda, este me ferirá!' Richard Wagner estava então mergulhado na sua composição. Estavam destinados a se ferirem mutuamente, esses dois homens cuja amizade se ia iniciar. ${ }^{6}$

5. Formada pelas seguintes peças: $O$ ouro de Remo (prelúdio), $A$ Valquiria, Siegfried e $O$ crepúsculo dos deuses.

6. HALÉVY, 1989. p. 55. 
O encontro entre Nietzsche e Wagner se dá quando este ainda não vivencia os sucessos e armadithas que o mito do wagnerismo obteve junto à cultura oficial da época. Ao contrário, o filósofo é, antes, um cúmplice intimista de mais um conturbado caso de amor de Wagner. Este raptara Cosima - filha de Lizst - , provocando um grande escândalo na sociedade, e isolou-se com a amada em Triebschen, às margens do lago de Lucerna.

Assim, a casa de campo onde habitava o insurreto casal torna-se espaço mitificado por Nietzsche a abrir um vértice (de solidão) para compor o inusitado triângulo. Em resposta aos diversos convites para que visitasse Roma, feitos pelo amigo Erwin Rohde, Nietzsche afirmaria ter também a sua Itália, a sua renascença humanística:

mas só posso ir lá aos sábados e aos domingos. A minha Itália chama-se Triebschen, e nela me sinto como em casa. Nestes últimos tempos, estive lá em quatro ocasiões quase que seguidas(...) Meu caro amigo, o que aprendo e vejo, o que ouço por lá, é impossível de dizer. Schopenhauer e Goethe, Píndaro e Ésquilo, ainda vivem, asseguro-lhe. ${ }^{7}$

Ao mesmo tempo que Wagner compunha a partitura do Crepúsculo dos deuses, Nietzsche delineava, na clave estético-filosófica, a sua "partitura" de Origem da tragédia, a partir de estudos que desenvolvia sobre a cultura helênica. Neles, Nietzsche priorizava os primeiros tempos daquela civilização: de Homero a Ésquilo. Ao optar por esta Grécia dionisíaca, trágica e misteriosa, o jovem filósofo descartava os ditames daquela Grécia socrática que se centralizava no eixo do Logos e da lógica.

O texto de Nietzsche, resultado de uma série de conferências que proferiu na Basiléia, tanto serviu para aproximá-lo mais ainda da intimidade do casal, quanto para resgatar a tragédia grega de antes daquela influência decadente da época de Sócra-

7. Ibidem, p. 63. tes. Após o primeiro momento, "depois de ter atingido sua perfeição pela reconciliação da 'embriaguez e da forma' de Dionísio e Apolo" ${ }^{\prime 8}$, até então complementares entre si, surge a ruptura entre esses dois deuses-metáforas. Se, por um lado, Apolo representava a harmonia, a clareza e a ordem, por outro lado, Dionísio simbolizava a desordem, a exuberância e a música; num claro jogo interdependente entre a razão e a emoção.

Com a expulsão de Dionísio de dentro da cidadeEstado, se afigurou por completo o lado apolíneo da civilização grega. Ao espalhar suas labaredas de racionalidade no tempo e no espaço da cultura ocidental, Apolo acabou tornando-se a "escala tonal" dominante e única. Sendo assim, para Nietzsche, o retorno do dionisismo estaria contido na música de Wagner, principalmente no Tristão e Isolda. Aí se experimentaria "um mergulho para além da individuação, no Uno primordial, onde a dor da existência é potenciada e superada pela catarse trágica". ${ }^{9}$

Os dez anos de contato que envolveram o músico e o filósofo - interrompidos aproximadamente em 1878 - testemunharam a lenta e gradual mudança de rota na amizade entre os dois. Já em Humano, demasiado humano, se sabe, como afirma Hollinrake, uma "atitude dissidente" de Nietzsche, onde alguns apontamentos começam a revelar a "ambivalência do pensamento e sentimento característico da posição" 10 do filósofo.

O lançamento de $O$ caso Wagner, em 1888, e a organização dos fragmentos que comporão Nietzsche contra Wagner radicalizam o tom de amargura, ódio e... amor, provocado pela conflituosa e passional relação dos dois atores, grandes protagonistas do decadentismo burguês e da aurora da modernidade. A obsessão fantasmática de Nietzsche criava portentosas asas e, assustadoramente, se firmava, à medida que se distanciava (temporal e espacialmente) do seu passado: objeto do desejo.

\footnotetext{
8. CHAUÍ, (s. d. ), p. 627.

9. WISNIK, 1987, p. 218.

10. HOLLINRAKE, 1986. p. 9.
} 
ENSAIO

\section{SEGUNDO ATO}

Possa a noite durar para nós eternamente.

(Tristão e Isolda)

O tema da paixão torna-se nos, escritos de Nietzsche, um "leitmotiv" que irá orquestrar seu pensamento, tal qual os motes melódicos que Wagner inaugura, sistemática e ordenadamente, para a música ocidental. Poção mágica restauradora que rege os caminhos de sua "ética" e existência, ela é capaz de alimentar e energizar a força de vida, no momento em que amor e dor, alegria e tristeza, emoção e razão, prosseguem em seu embate sublime.

Se, em Tristão e Isolda, paixão e casamento são pontas de um "iceberg" que nunca se encontrarão, por outro lado, no ideário nietzscheano, a paixão recebe a mesma carga valorativa da amizade: pólos superiores nas relações humanas. O filósofo afirma ter sido o casamento um invento "para os seres humanos medianos, que não são aptos nem para o grande amor nem para a grande amizade". Portanto, é na clave paixão-amizade (potencializada ao infinito), que estão presentes as conjunções e disjunções entre Nietzsche e Wagner. A suspensão da paixão deve-se, talvez, à impossibilidade de concretude de um tipo de "casamento" feito somente "para aqueles, rarissimos, que são aptos tanto para o grande amor quanto para a grande amizade" ${ }^{11}$

As bodas de Nietzsche com a música chegaram às raias da apatia, no momento em que o autor terminou de redigir $O$ caso Wagner. Da herança deixada por Dionísio, só a obra de Bizet foi tolerada. O estilo de composição e de orquestração do autor de Carmen tomou-se para Nietzsche mais um antidoto para combater os malefícios causados pelos sons abissais de Wagner - mesmo depois da morte do compositor em 1883 - , do que, como explicava, um meio de libertação via "leveza e suavidade" da música de Bizet.

11. WISNIK, 1987. p. 21.
Se para Nietzsche a obra desse seu novo amor libertava, por outro lado, não havia obra de Wagner que fosse "libertadora". Em termos meramente estéticos, o filósofo criticava a orientação melódico-acústica que Wagner empreendia em suas criações: "brutal, artificial e 'ingênuo', simultaneamente, e que, assim, fala ao mesmo tempo aos três sentidos da alma moderna". ${ }^{12}$

Ao preterir Isolda em favor de Carmen, Nietzsche recorria aos valores da paixão amena, que não se permitia a uma grandiloqüência cênica e orquestral. Troca, então, a bruma imprecisa, densa e enigmática da música alemã pela "sensibilidade meridional, morena, queimada" 13 da obra de Bizet - espécie de dionisismo anti-germânico que mais se amorena quanto maior for a dosagem de sons mouriscos em sua partitura.

Wagner e Nietzsche - duas embarcações que, cada vez mais, seguem rotas distintas e mares (aparentemente) desemelhantes - acabam se encontrando, enquanto precursores da modernidade. Wagner e Nietzsche protagonizam a decadência que substancializa o século XIX, com a diferença de que, segundo palavras do próprio filósofo, "eu, compreendi-o, resisti a isso com todas as minhas forças. O filósofo, em mim, resistiu" ${ }^{14}$.

A querela entre esses dois criadores, na verdade, flagra o raiar da modernidade em suas diferentes frentes de expressão: a elipse cartesiana e o excesso barroco. Ironicamente, o ex-discípulo afirma que "pela boca de Wagner (...) a modernidade fala a sua linguagem mais intima: não esconde nem os seus vícios, nem as suas virtudes, perdeu todo e qualquer pudor ${ }^{15}$. Ao criticar o projeto grandioso que Wagner propõe e constrói, ("Tudo aí parece grande, o próprio Wagner parece grande... Que astuciosa cascavel!"16), Nietzsche chama a ateção para uma faceta da modernidade de que ele prprio tende a se desviar cada vez mais à medida que

12. NIETZSCHE, O caso Wagner, p. 29-30.
13. Ibidem., p. 32.
14. Ibidem., p. 24.
15. Ibidem., p. 25.
16. Ibidem., p. 34.

R. Est. Lit., Belo Horizonte, v. 1, n. 1, p. 75 - 81, out. 1993 
seus escritos filosóficos amadurecem: a retórica do simultâneo, formulada através de paradoxos e pela acumulação inebriante de dados e informações. "Quem é que pelos seus movimentos foi levado à cena? Quem é que sempre cultivou o excesso?"17. Se o jovem Nietzsche, que via o espírito trágico dos tempos pré-socráticos reencarnado na Alemanha unificada dos novecentos, era àquele altura símile da posição estético-reiterativa de Wagner, o maduro e amargo Nietzsche - regido ainda pelo signo da passionalidade e da polêmica - opta pela harmonia clássica no tom estrutural de seu pensamento. Bizet - "que é leve pois tudo que é divino se move delicadamente"18 - serve, então, de metáfora para o seu programa que, aparentemente, se desviava da essência do projeto da modernidade.

Para Nietzsche, a ópera de Wagner, querendo se apresentar como "ópera da salvação", tornou-se expressão flagrante do decadentismo burguês, alimentado tanto por uma concepção fatalista do cristianismo quanto pela excessiva dosagem do pensamento filosófico de Schopenhauer. Utilizando-se das mesmas metáforas marítimas encontradas na obra wagneriana, Nietzsche compara o (ex) amigo a uma nave que

seguiu durante muito tempo alegremente seu curso. Sem qualquer dúvida, era aí que Wagner conduzia a sua mais elevada procura. O que se passou então? Uma catástrofe. $\mathrm{O}$ navio embateu contra um escolho. Wagner afundou-se no escolho de uma concepção do mundo contrária à sua ${ }^{19}$.

Wagner, artista da decadência que fez de sua música uma doença - da mesma forma que para Nietzsche o compositor também o era ("A minha mais marcante experiência foi uma cura. Wagner foi apenas uma das minhas doenças ${ }^{\prime 20}$ ), realiza a confluência das variadas maneiras de expressão

17. NIETZSCHE. O caso Wagner, p. 65.

18. Ibidem., p. 30.

19. Ibidem, p. 39.

20. Ibidem., p. 24. artísticas a partir do "leitmotiv" musical. Defensor da música enquanto forma de expressão que se restringisse à sua concepção rítmica, melódica e harmônica, Nietzsche faz sua crítica a Wagner, "homem de teatro", pelo seu grandioso projeto de reunir texto, música e interpretação dramática numa mesma cena: a ópera.

Em Wagner, há, à partida: alucinação, não de sons, mas de gestos. É só posteriormente que ele procura uma semiótica sonora que a eles se adaptem. (...) $\mathrm{O}$ que lhe vem em primeiro lugar ao espírito é uma cena de efeito absolutamente seguro, é uma autêntica 'actio' onde os gestos se destacam com uma nitidez de 'haut-reliefs', uma cena propriamente 'arrebatadora', ${ }^{21}$

No epílogo de $O$ caso Wagner, Nietzsche fornece sua concepção de modernidade quando fala das "forças" específicas que dominam em determinadas épocas históricas via acessibilidade e inacessibilidade das virtudes.

Ou possui as virtudes da vida crescente; então, por razões muito profundas, resiste com todas as suas forças às virtudes da vida declinante. Ou é ela própria vida declinante - tem então necessidade das virtudes do declínio, e detesta tudo o que se justifica apenas pela plenitude, pela superabundância de forças. A estética está indissociavelmente ligada a condições biológicas: há uma estética de 'décadence', há uma estética clássi$\mathrm{ca}^{22}$.

É nessa dicotomia entre harmonia clássica e desordem barroca que está pousada esta passional querela de voz univoca; seus barcos singraram mares opostos em busca de encontro em algum ponto seguro.

"Éramos amigos e nos tornamos estranhos um ao outro. Mas é bom que seja assim, e

21. NIETZSCHE. O caso Wagner, p. 48 e 53.

22. Ibidem., p. 73. 
não o procuraremos dissimular nem disfarçar, como se devêssemos ter vergonha disso. Como dois navios que seguem cada um seu rumo e seu próprio objetivo: assim sem dúvida poderemos nos encontrar e celebrar festas entre nós como já o fizemos antes e então os bons navios repousavam lado a lado no mesmo porto, sob o sol, tão tranqüilos que se poderia dizer que já tinham chegado ao seu objetivo e tivessem tido a mesma destinação. Mas em seguida o apelo irresistivel da nossa missão nos levaria de novo um para longe do outro, cada um sobre mares, sob sóis diferentes - talvez para nos revermos uma vez mais, mas sem nos reconhecermos: mares e sóis diferentes provavelmente nos fizeram mudar!"

(Friedrich Nietzsche)

\begin{abstract}
Tristan and Isolde as a metaphor for the union and disaggregation between Nietzsche and Wagner. Dionysus spirit and apollinean spirit: The Birth of Tragedy. First encounters and the building up of passion. A strange triangle: Nietzsche, Wagner and Cosima. The fall of the relationship in Human, All-Too-Human and The Wagner Affair. Bizet and the Mediteranean dionysism. The disputes of dissonance: the dawn of modernity in its several vanguards of expression.
\end{abstract}

\section{REFERÊNCIAS BIBLIOGRÁFICAS}

1. CHAUİ, Marilena.História das grandes idéias do mundo ocidental. São Paulo: Abril Cultural, [s.d.]. v. 3, p. 627: Nietzsche.

2. HALÉVY, Daniel. Nietzsche; uma biografia. Rio de Janeiro: Campus, 1989.

3. HOLLINRAKE, Roger. Nietzsche, Wagner e a filosofia do pessimismo. Rio Janeiro: Jorge Zahar, 1986.

4. NIETZSCHE, Friedrich. $O$ caso Wagner. Porto: Rés, [s.d.].

5. - Gaia ciência.Lisboa: Guimarães e Cia., 1977.

6. ____ Origem da tragédia. 2.ed. Lisboa: Guimarães e Cia., 1972.

7. WISNIK, José Miguel. A paixão dionisíaca. In: NOVAES, Adauto (org.). Os sentidos da Paixão. São Paulo: Companhia das Letras; Rio de Janeiro: FUNARTE, 1987. 